\title{
Prognostic impact of the prognostic nutritional index in cases of resected oral squamous cell carcinoma: a retrospective study
}

\author{
Atsushi Abe ${ }^{*} \mathbb{D}$, Hiroki Hayashi, Takanori Ishihama and Hiroshi Furuta
}

\begin{abstract}
Background: The systemic inflammatory response and nutritional status of patients with malignant tumors are related to postoperative results. We examined the usefulness of the prognostic nutritional index (PNI) as a prognostic tool in patients with oral squamous cell carcinoma who underwent radical surgery.

Methods: From 2008 to 2019, 102 patients (73 males, 29 females; age, 65.6 \pm 9.8 years) who visited our hospital and underwent surgical therapy were included in this study. The endpoint was the total survival period, and the evaluation markers included the lymphocyte count and albumin level in peripheral blood obtained 4 weeks preoperatively, age, sex, alcohol consumption, smoking history, site of the tumor, pathological stage, and surgery status. The PNI was calculated using serum albumin levels and the peripheral blood lymphocyte count. The relationship between the PNI and patient characteristics were analyzed using Fisher's exact test. The Kaplan-Meier method was used to evaluate the survival rate. The survival periods were compared using the log-rank method. We evaluated the prognostic factors for overall survival (OS) and disease-free survival (DFS) in a logistic regression model.
\end{abstract}

Results: The tumor sites included the maxilla $(n=12)$, buccal mucosa $(n=11)$, mandible $(n=17)$, floor of the mouth $(n=9)$, and tongue $(n=53)$. The number of patients with stage I, II, III, and IV oral cancers was $28(27.5 \%), 34(27.5 \%)$, $26(33.3 \%)$, and 14 (13.7\%), respectively. During the observation period, 21 patients died of head and neck cancer. The optimal cut-off PNI value was 42.9, according to the receiver operating characteristic analysis. The proportion of patients with a short OS was lower in those with PNI higher than 42.9, and the 5-year OS in patients with PNI higher and lower than the cut-off value was $62.3 \%$ and $86.0 \%$, respectively $(P=0.0105)$.

Conclusions: The OS of patients with $\mathrm{PNI}<42.9$ was lower than that of patients with $\mathrm{PNI} \geq 42.9$. The $\mathrm{PNI}$, which is a preoperative head-to-foot inflammatory marker, can help in estimating the prognosis of oral cancer.

Keywords: Oral cancer, Systemic inflammation, Biomarkers, Prognosis, Nutritional status

\section{Background}

Although the treatment of oral cancer and the posttreatment quality of life have improved, late metastasis and recurrence are possible complications $[1,2]$. The prognostic factors for patients with oral cancer include tumor depth, vascular and neural invasion, cervical

*Correspondence: atsushi.a@ekisai.or.jp

Department of Oral and Maxillofacial Surgery, Nagoya Ekisaikai Hospital,

4-66 Syounen-cho Nakagawa-ku, Nagoya 454-8502, Japan lymph node metastasis, and extranodal invasion [3-8]. However, pathological findings and staging alone cannot completely define prognosis. In cancer involving other organ systems, such as gastrointestinal cancer, hostrelated factors like nutritional indicators and systemic inflammatory responses, are useful in evaluating survival and recurrence, and the prognosis has been reported to relate with these factors [9-19]. The systemic inflammatory response is not only an indicator of the nutritional status $[20,21]$ but is also useful as a prognostic tool 
based on mechanisms different from those underlying tumor markers [22]. A previous report has examined the systemic inflammatory response and the effect of the nutritional status in patients with oral cancer receiving radiation or chemotherapy; however, there are few reports on patients having undergone surgical therapy $[10,23]$.

The prognostic nutritional index (PNI) is evaluated using the serum albumin level and the lymphocyte count. Albumin has been reported as a biomarker of the nutritional status, and its level has been identified to be related to the co-morbidities and the prognosis for certain cancers $[24,25]$. It evaluates the susceptibility to infection by assessing malnutrition associated with insufficient protein intake and the evaluation of biological defense capabilities using tests combining evaluation of visceral protein status and immunological function. The lymphocytes take part in cell-mediated immunity and inhibit proliferation and invasion of cancer cells [26]. Therefore, PNI reflects the nutritional status and immunological state of the patient.

The clinicopathologic utility of the PNI has been studied for several malignant tumors, and it has been reported as an independent prognostic tool to assess patient overall survival (OS) $[21,27,28]$. However, the prognostic value of the PNI and its clinicopathologic correlation in patients with oral cancer remains unknown. Therefore, we aimed to examine whether the preoperative PNI could affect the 5-year survival rates in patients who have undergone surgical treatment for oral cancer.

\section{Methods}

\section{Patients and evaluating parameters}

We performed a cross-sectional analysis, including patients with primary oral cancer. We included 102 out of the 117 patients who visited the Nagoya Ekisaikai Hospital and underwent radical surgical therapy for oral squamous cell carcinoma between Jan 2008 and June 2019. Fifteen patients were excluded due to recurrence, metabolic diseases (such as diabetes mellitus), missing data, or the case that treatment was not able to continue because of intention and the overall status of the patients. Data of 102 patients (73 men, 29 women; mean age, $65.6 \pm 9.8$ years; the Performance Status(PS) criteria for treatment protocol followed were as follows: (1) Extent of resection was determined using a clinical examination, imaging, and evaluation of cervical lymph node metastasis, degree of differentiation, and degree of invasion. (2) Safety margins for resection were kept at $1 \mathrm{~cm}$. (3) Prophylactic neck dissection was not performed for patients without lymph node involvement. However, when the case at elevated risk for the potential metastasis and an ablative range was big, and reconstructive operation was necessary for cT3/T4N0, the dissection of the neck was performed. (4) Neoadjuvant chemotherapy or radiotherapy was not administered. (5) When more than two histopathologically confirmed extracapsular lymph nodes were present or the safety margin of the resection stump was inadequate, postoperative chemoradiotherapy was administered. The average observation period was 48.1 months (6-252.1 months). The examined factors were the survival periods and the long-term prognosis based on PNI grouping. We assessed clinical background factors (preoperative peripheral blood lymphocyte and monocyte counts in relation to age, sex, alcohol consumption history, smoking history, site of the primary tumor, TNM classification, and tumor stage) to examine their association with the OS and DFS (disease-free survival). Lymphocyte and neutrophil counts were measured from peripheral blood samples obtained within 4 weeks before radical surgery. Oral cancer evaluation was based on the findings obtained from visual examination, palpation, computed tomography, and magnetic resonance imaging, and an assessment of the site of occurrence and progression was also performed. Tumor stage was defined according to the Union for International Cancer Control classification [29]. The overall health was evaluated using the body mass index (BMI), albumin levels, and a preoperative examination. The PNI, a systemic inflammation biomarker, was calculated using the serum albumin level and peripheral blood lymphocyte count. The OS was defined as the period between the diagnosis of OSCC and either death. DFS was defined as the time between the first operation to the first documented recurrence, metastasis, or death. Patients, who had not passed away at the end of the investigated period, or patients in whom it was unclear if they had passed away, were censored. The formula used for PNI calculation is as follows [30]:

$$
\mathrm{PNI}=[10 \times \text { serumalbuminlevel }(\mathrm{g} / \mathrm{dL})]+\left[0.005 \times \text { totalperipherallymphocytecount }\left(\text { permm }^{3}\right)\right]
$$

intended for the patients of 1 or 2 were analyzed in this study. The clinical and histopathological features and the treatment course of the patients were retrospectively assessed using their medical records. The inclusion
The study was approved by the Ethical Review Board of Nagoya Ekisaikai Hospital (approval no. 2019-046), and written informed consent was obtained from all participants. 


\section{Statistical analysis}

We conducted a univariate analysis to examine the association of the PNI with the prognosis. Then, we performed multivariate analysis using selected prognosisrelated factors. The multivariate analysis was performed by calculating the hazard ratio (HR) and $95 \%$ confidence interval (CI) using the Cox proportional hazards model. Patient characteristics and their relationships with the PNI score were analyzed using Fisher's exact test. Analyses of the associations between PNI multiple clinicopathological parameters were conducted using Fisher's exact test or Mann-Whitney U test accordingly.

The PNI cut-off level was set using the receiver operating characteristic (ROC) curve and the area under the curve (AUC) analysis. The ratios of patient OS and DFS were calculated with the Kaplan-Meier method and compared with the log-rank test. Prognostic factors for the OS and DFS were adjusted in a Cox regression model before the evaluations. All analyses were performed with a two-sided test, and P values of 0.05 or less were considered statistically significant. Kaplan-Meier curves of the estimated OS and DFS were generated, and comparisons between the groups were performed using the log-rank test. The multivariate analysis used a Cox proportional hazards model. Each variable was deleted by the model only when the supporting $\mathrm{P}$ values in the univariate analysis were 0.1 or higher. All statistical analyses were performed using EZR (Jichi Medical University, Saitama Japan), a graphical user interface for R Ver. 2.8.1 (The $R$ Foundation for Statistical Computing, Vienna, Austria).

\section{Results}

\section{Clinicopathological characteristics of the patients}

Table 1 shows the characteristics of the patients included in this study. The average age of the patients was $65.6 \pm 9.8$ years, and the number of men and women was $73(71.6 \%)$ and $29(28.4 \%)$, respectively. Sixty patients $(58.8 \%)$ had a history of smoking. The BMI ranged from 33.5 to $14.9 \mathrm{~kg} / \mathrm{m}^{2}$ (mean \pm standard deviation, $22.8 \pm 3.9 \mathrm{~kg} / \mathrm{m}^{2}$ ). The PNI ranged from 49.4 to 38.8 (mean, $44.0 \pm 2.14$ ). We used a ROC curve analysis to evaluate whether the PNI could predict DFS or OS. ROC analyses showed that the optimal PNI was 42.9 (OS: sensitivity- 69.2, specificity- 0.583; AUC $=0.62$; DFS: sensitivity- 75.8, specificity- 0.575; AUC $=0.66$ ) (Figs. 1, 2). The PNI cut-off value was therefore set at 42.9 , and the patients were divided into low PNI $(<42.9$; OS: $n=37$ [36.3\%]; DFS: $\mathrm{n}=35$ [34.3\%]) and high PNI (42.9 $\leq$; OS: $\mathrm{n}=65$ [63.7\%]; DFS: $\mathrm{n}=67$ [65.7\%]) groups.

\section{The OS and DFS, according to the PNI}

The relationship between specific clinicopathological factors and the OS and DFS is summarized in Tables 2,
Table 1 Characteristics of the patients

\begin{tabular}{|c|c|c|}
\hline Variables $(n=102)$ & Group & n (\%) \\
\hline Age (mean $\pm S D)$ & & $65.6 \pm 9.8$ \\
\hline \multirow[t]{2}{*}{ Sex } & Male & $73(71.6 \%)$ \\
\hline & Female & $29(28.4 \%)$ \\
\hline \multirow[t]{2}{*}{ Smoking status } & Smoker & $60(58.8 \%)$ \\
\hline & Never-smoker & $42(41.2 \%)$ \\
\hline \multirow[t]{2}{*}{ Alcohol } & Nondrinker & $43(42.2 \%)$ \\
\hline & Drinker & $59(57.8 \%)$ \\
\hline BMI (mean $\pm S D)$ & & $22.78 \pm 3.87$ \\
\hline \multirow[t]{5}{*}{ Tumor site } & Maxilla & $12(11.8 \%)$ \\
\hline & Buccal & $11(10.8 \%)$ \\
\hline & Mandible & $17(16.7 \%)$ \\
\hline & Floor of mouth & $9(8.8 \%)$ \\
\hline & Tongue & $53(52.0 \%)$ \\
\hline \multirow[t]{4}{*}{ T } & 1 & $30(29.4 \%)$ \\
\hline & 2 & $53(52.0 \%)$ \\
\hline & 3 & $12(11.8 \%)$ \\
\hline & 4 & $7(6.9 \%)$ \\
\hline \multirow[t]{3}{*}{ N } & 0 & $75(73.5 \%)$ \\
\hline & 1 & $22(21.6 \%)$ \\
\hline & 2 & $5(4.9 \%)$ \\
\hline \multirow[t]{4}{*}{ Stage } & 1 & $28(27.5 \%)$ \\
\hline & 2 & $34(33.3 \%)$ \\
\hline & 3 & $27(26.5 \%)$ \\
\hline & 4 & $13(12.7 \%)$ \\
\hline \multirow[t]{3}{*}{ Tumor differentiation } & Well & $52(51.0 \%)$ \\
\hline & Moderately & $41(40.2 \%)$ \\
\hline & Poorly & $9(8.8 \%)$ \\
\hline \multirow[t]{2}{*}{ Lymphovascular invasion } & No & $70(68.6 \%)$ \\
\hline & Yes & $32(31.4 \%)$ \\
\hline \multirow[t]{2}{*}{ Vascular invasion } & No & $97(95.1 \%)$ \\
\hline & Yes & $5(4.9 \%)$ \\
\hline \multirow[t]{2}{*}{ Perineural invasion } & No & $92(90.2 \%)$ \\
\hline & Yes & $10(9.8 \%)$ \\
\hline \multirow{2}{*}{$\begin{array}{l}\text { Close margin ( }<5 \mathrm{~mm} \text { by histopa- } \\
\text { thology) }\end{array}$} & No & $95(93.1 \%)$ \\
\hline & Yes & $7(6.9 \%)$ \\
\hline \multirow[t]{2}{*}{ Postoperative treatment } & No & $76(74.5 \%)$ \\
\hline & Yes & $26(25.5 \%)$ \\
\hline Neutrophil (mean \pm SD) & & $58.89 \pm 9.15$ \\
\hline Total lymphocytes (mean \pm SD) & & $1857.48 \pm 711.19$ \\
\hline Alb (mean $\pm S D)$ & & $4.03 \pm 0.24$ \\
\hline $\mathrm{CRP}($ mean $\pm \mathrm{SD})$ & & $0.35 \pm 0.58$ \\
\hline PNI (mean \pm SD) & & $44.01 \pm 2.14$ \\
\hline
\end{tabular}

$B M I$ body mass index, CRP C-reactive protein, $P N /$ prognostic nutritional index

3. The Kaplan-Meier survival curve outlining the relationship between the PNI and the OS and DFS rate $(\mathrm{P}<0.001)$ is shown in Figs. 3 and 4. The group with low PNI showed significantly lower rates of OS and DFS 


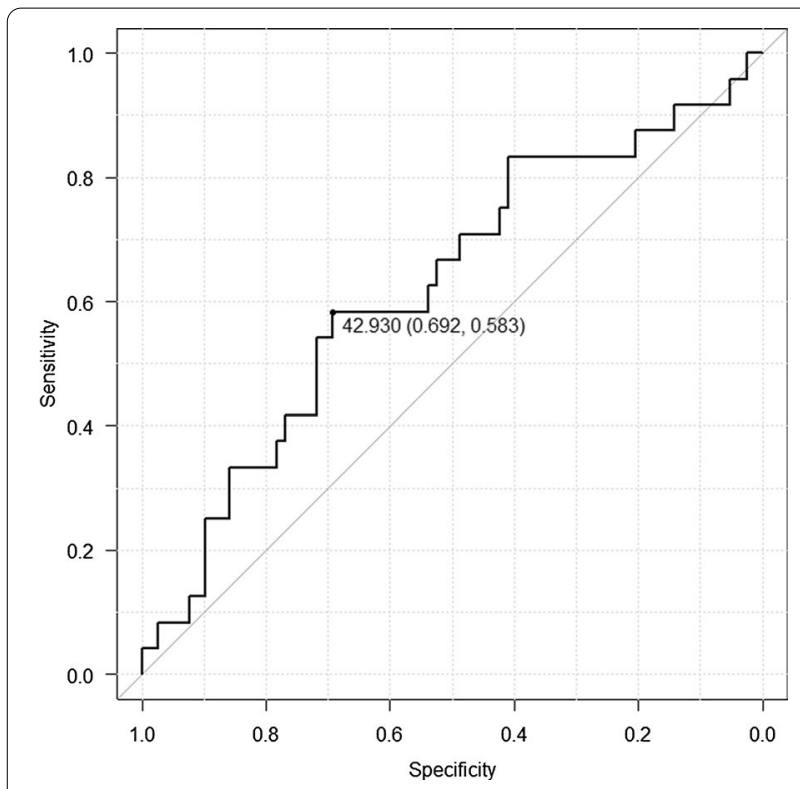

Fig. 1 ROC curve for the PNI. The continuous variables PNI and OS were used as the test and state variables, respectively. The PNI cut-off value was 42.9 with the area under the curve, sensitivity, and specificity being $0.634,0.765$, and 0.524 , respectively. $R O C$ receiver operating characteristic, $P N /$ prognostic nutritional index, OS overall survival

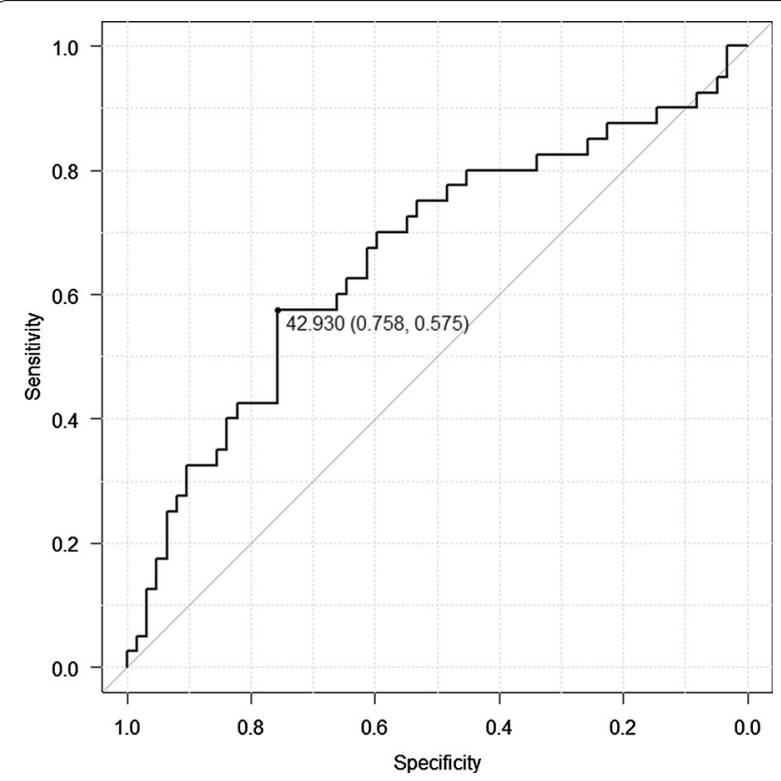

Fig. 2 ROC curve for the PNI. The continuous variables PNI and DFS were used as the test and state variables, respectively. The PNI cut-off value was 42.9 , with the area under the curve, sensitivity, and specificity being $0.663,0.758$, and 0.575 , respectively. $R O C$ receiver operating characteristic; $P N /$ prognostic nutritional index, DFS disease-free survival compared to the group with high PNI. Univariate analysis revealed that the stage $(\mathrm{P}=0.016)$, vascular invasion $(\mathrm{P}=0.014)$, pre-treatment serum CRP level $(\mathrm{P}=0.002)$, and PNI $(\mathrm{P}=0.011)$ were associated with the rate of $\mathrm{OS}$ (Table 2); however, univariate analysis revealed no association between the rate of DFS and the stage $(\mathrm{P}=0.042)$, albumin level $(P=0.045)$, pre-treatment serum $C R P$ level $(\mathrm{P}=0.007)$, lymphovascular invasion $(\mathrm{P}=0.001)$, postoperative treatment $(\mathrm{P}=0.0002)$, and PNI $(\mathrm{P}=0.006)$ (Table 3). As a result of the analysis, multicollinearity was absent. We included the factors included in the univariate analysis along with important prognostic factors (histopathological differentiation, surgical margin, vascular and perineural invasion, and postoperative treatment) as covariates in the multivariate analysis. The multivariate analysis showed that only the CRP level (HR 2.99; 95\% CI 11.20-7.46; $\mathrm{P}=0.019$ ), perineural invasion (HR 3.73; 95\% CI 1.06-13.09; $\mathrm{P}=0.04$ ), and PNI (HR 0.32; 95\% CI $0.13-0.79 ; \mathrm{P}=0.013$ ) were associated with the rate of OS (Table 4). The multivariate analysis also showed that the margin (HR 4.10; 95\% CI 1.13-14.94; $\mathrm{P}=0.032$ ), postoperative treatment (HR 3.71; 95\% CI 1.65-8.33; $\mathrm{P}=0.0015$ ), and the PNI (HR-0.27; 95\% CI 0.13-0.54; $\mathrm{P}=0.0024)$ were independent predictors of the DFS (Table 5).

\section{Discussion}

In some studies, PNI has been confirmed as a new prognostic tool for cancer, and a low PNI has been shown to be significantly associated with lower survival for pancreatic cancer, hepatocellular carcinoma, esophageal cancer, gastric cancer, colorectal cancer, renal cell carcinoma, and ovarian cancer [31-37]. In other reports, the cutoff value of PNI used to predict prognosis was 42-47.8. The results of our retrospective analysis showed that low preoperative PNI and high CRP levels were prognostic factors for poorer OS and DFS in patients with oral cancer. In this study, we divided the patients into two groups based on a PNI cut-off value of 42.9 derived from the ROC curve, and we compared the clinical background factors in the two groups. The cut-off value of 42.9 that we used in this study is within the range used in previous studies; therefore, it can be argued that PNI is a practical tool to assess postoperative prognosis [38-40]. In the multivariate analysis, a low PNI, a high CRP level, and perineural invasion were significantly associated with poorer OS. Significant differences were also observed in the HR (Hazard Ratio) with respect to the surgical margin, postoperative treatment, and PNI in the multivariate analysis for DFS. Additionally, the two groups showed differences in the DFS and the 5-year OS. These results suggest that the low PNI group has a poorer preoperative nutritional status and a higher degree of inflammatory 
Table 2 Univariate analysis of the associations between the clinicopathological characteristics of the patients and their prognostic variables and overall survival

\begin{tabular}{|c|c|c|c|c|c|c|}
\hline Variables & Group & $n$ & Survival rate (\%) & $P$ value & HR & $95 \% \mathrm{Cl}$ \\
\hline \multirow[t]{2}{*}{ Age } & $<66$ & 51 & 81.4 & 0.326 & & \\
\hline & $66 \geqq$ & 51 & 71.7 & & 1.33 & $0.31-5.64$ \\
\hline \multirow[t]{2}{*}{ Sex } & Male & 73 & 72.8 & 0.472 & & \\
\hline & Female & 29 & 88.5 & & 3.58 & $0.41-31.10$ \\
\hline \multirow[t]{2}{*}{ Smoking status } & Smoker & 60 & 70.5 & 0.114 & & \\
\hline & Never-smoker & 42 & 87.3 & & 0.19 & $0.03-1.39$ \\
\hline \multirow[t]{2}{*}{ Alcohol } & Nondrinker & 43 & 89.4 & 0.101 & & \\
\hline & Drinker & 59 & 67.5 & & 1.82 & $0.33-10.10$ \\
\hline \multirow[t]{2}{*}{ BMI } & $22.4<$ & 52 & 75.4 & 0.977 & & \\
\hline & $22.4 \geqq$ & 50 & 78.2 & & 1.03 & $0.29-3.76$ \\
\hline \multirow[t]{2}{*}{$\mathrm{T}$} & $\leqq 2$ & 83 & 77.8 & 0.671 & & \\
\hline & $3 \geqq$ & 19 & 71.8 & & 0.13 & $0.03-0.64$ \\
\hline \multirow[t]{2}{*}{ N } & $\leqq 2$ & 75 & 76.0 & 0.646 & & \\
\hline & $3 \geqq$ & 27 & 77.1 & & 0.03 & $0.00-0.22$ \\
\hline \multirow[t]{2}{*}{ Stage } & $\leqq 2$ & 62 & 87.1 & 0.016 & & \\
\hline & $3 \geqq$ & 40 & 63.5 & & 34.3 & $5.99-19.640$ \\
\hline \multirow[t]{2}{*}{ Grade } & Well/moderately & 93 & 76.4 & 0.399 & & \\
\hline & Poorly & 9 & 77.8 & & 0.14 & $0.02-1.18$ \\
\hline \multirow[t]{2}{*}{ Lymphovascular invasion } & No & 70 & 81.6 & 0.22 & & \\
\hline & Yes & 32 & 67.9 & & 0.81 & $0.22-2.94$ \\
\hline \multirow[t]{2}{*}{ Vascular invasion } & No & 97 & 78.0 & 0.014 & & \\
\hline & Yes & 5 & 60.0 & & 1.73 & $0.38-7.90$ \\
\hline \multirow[t]{2}{*}{ Perineural invasion } & No & 92 & 77.8 & 0.062 & & \\
\hline & Yes & 10 & 70.0 & & 6.11 & $1.02-36.57$ \\
\hline \multirow[t]{2}{*}{ Neutrophils } & $<59.6$ & 51 & 80.2 & 0.092 & & \\
\hline & $\geqq 59.6$ & 51 & 73.0 & & 4.93 & $1.21-20.00$ \\
\hline \multirow[t]{2}{*}{ Total lymphocytes } & $<1730$ & 51 & 74.7 & 0.776 & & \\
\hline & $\geqq 1730$ & 51 & 80.8 & & 1.42 & $0.44-4.65$ \\
\hline \multirow[t]{2}{*}{ Alb } & $<4$ & 55 & 75.0 & 0.57 & & \\
\hline & $\geqq 4$ & 47 & 79.1 & & 1.42 & $0.16-12.92$ \\
\hline \multirow[t]{2}{*}{ CRP } & $<0.2$ & 59 & 86.3 & 0.002 & & \\
\hline & $\geqq 0.2$ & 43 & 62.8 & & 5.67 & $1.50-21.49$ \\
\hline \multirow[t]{2}{*}{$\mathrm{PNI}$} & $<42.93$ & 35 & 64.3 & 0.011 & & \\
\hline & $\geqq 42.93$ & 67 & 84.1 & & 0.15 & $0.02-1.14$ \\
\hline \multirow[t]{2}{*}{ Postoperative treatment } & No & 76 & 80.5 & 0.069 & & \\
\hline & Yes & 26 & 66.5 & & 1.35 & $0.34-5.39$ \\
\hline \multirow{2}{*}{$\begin{array}{l}\text { Close margin ( }<5 \mathrm{~mm} \text { by histopa- } \\
\text { thology) }\end{array}$} & No & 95 & 76.6 & 0.433 & & \\
\hline & Yes & 7 & 85.7 & & 2.48 & $0.31-20.02$ \\
\hline
\end{tabular}

$B M I$ body mass index, $C R P$ C-reactive protein, $P N /$ prognostic nutritional index

response than the high PNI group, resulting in poor prognosis. The PNI, which is estimated using the serum albumin level and the lymphocyte count, reflects the nutritional and immunological state of the patient. Previous studies have reported the PNI as a prognostic factor affecting OS for different malignancies [41-45].
Microenvironmental inflammation affects the growth of tumor cells and promotes angiogenesis and metastasis $[46,47]$. The immune system recognizes cancer cells and secretes, as a response, inflammatory cytokines, leading to hypercytokinemia [46-48]. Interleukin-8 (IL-8) and vascular endothelial growth factor (VEGF) are two cancer-associated cytokines. These cytokines cause the 
Table 3 Univariate analysis of the associations between the clinicopathological characteristics of the patients and their prognostic variables and DFS

\begin{tabular}{|c|c|c|c|c|c|c|}
\hline Variables & Group & $n$ & Survival rate & $P$ value & HR & $95 \% \mathrm{Cl}$ \\
\hline \multirow[t]{2}{*}{ Age } & $<66$ & 51 & 0.622 & 0.233 & & \\
\hline & $66 \geqq$ & 51 & 0.515 & & 1.37 & $0.55-3.38$ \\
\hline \multirow[t]{2}{*}{ Sex } & Male & 73 & 0.575 & 0.678 & & \\
\hline & Female & 29 & 0.569 & & 2.16 & $0.66-7.03$ \\
\hline \multirow[t]{2}{*}{ Smoking status } & Smoker & 60 & 0.569 & 0.951 & & \\
\hline & Never-smoker & 42 & 0.575 & & 0.6 & $0.19-1.87$ \\
\hline \multirow[t]{2}{*}{ Alcohol } & Nondrinker & 43 & 0.599 & 0.84 & & \\
\hline & Drinker & 59 & 0.548 & & 1.12 & $0.34-3.74$ \\
\hline \multirow[t]{2}{*}{ BMl } & $22.4<$ & 52 & 0.54 & 0.454 & & \\
\hline & $22.4 \geqq$ & 50 & 0.596 & & 0.44 & $0.18-1.11$ \\
\hline \multirow[t]{2}{*}{$\mathrm{T}$} & $\leqq 2$ & 83 & 0.573 & 0.674 & & \\
\hline & $3 \geqq$ & 19 & 0.545 & & 0.23 & $0.07-0.71$ \\
\hline \multirow[t]{2}{*}{ N } & $\leqq 2$ & 75 & 0.563 & 0.6 & & \\
\hline & $3 \geqq$ & 27 & 0.572 & & 0.08 & $0.02-0.32$ \\
\hline \multirow[t]{2}{*}{ Stage } & $\leqq 2$ & 62 & 0.669 & 0.0421 & & \\
\hline & $3 \geqq$ & 40 & 0.449 & & 4.46 & $1.34-14.81$ \\
\hline \multirow[t]{2}{*}{ Grade } & Well/moderately & 93 & 0.577 & 0.0665 & & \\
\hline & Poorly & 9 & 0.444 & & 1.15 & $0.25-5.21$ \\
\hline \multirow[t]{2}{*}{ Lymphovascular invasion } & No & 70 & 0.644 & 0.00152 & & \\
\hline & Yes & 32 & 0.389 & & 1.04 & $0.39-2.80$ \\
\hline \multirow[t]{2}{*}{ Vascular invasion } & No & 97 & 0.585 & 0.267 & & \\
\hline & Yes & 5 & 0.4 & & 0.86 & $0.22-3.34$ \\
\hline \multirow[t]{2}{*}{ Perineural invasion } & No & 92 & 0.565 & 0.554 & & \\
\hline & Yes & 10 & 0.6 & & 0.88 & $0.18-4.33$ \\
\hline \multirow[t]{2}{*}{ Neutrophils } & $<59.6$ & 51 & 0.664 & 0.0897 & & \\
\hline & $\geqq 59.6$ & 51 & 0.477 & & 1.28 & $0.56-2.90$ \\
\hline \multirow[t]{2}{*}{ Total lymphocytes } & $<1730$ & 51 & 0.508 & 0.33 & & \\
\hline & $\geqq 1730$ & 51 & 0.651 & & 0.67 & $0.28-1.58$ \\
\hline \multirow[t]{2}{*}{ Alb } & $<4$ & 55 & 0.478 & 0.0451 & & \\
\hline & $\geqq 4$ & 47 & 0.676 & & 0.32 & $0.10-0.99$ \\
\hline \multirow[t]{2}{*}{ CRP } & $<0.2$ & 59 & 0.657 & 0.00721 & & \\
\hline & $\geqq 0.2$ & 43 & 0.438 & & 1.53 & $0.66-3.55$ \\
\hline \multirow[t]{2}{*}{$\mathrm{PNI}$} & $<42.93$ & 38 & 0.378 & 0.00631 & & \\
\hline & $\geqq 42.93$ & 64 & 0.67 & & 0.61 & $0.23-1.61$ \\
\hline \multirow[t]{2}{*}{ Postoperative treatment } & No & 76 & 0.655 & 0.000221 & & \\
\hline & Yes & 26 & 0.337 & & 3.59 & $1.29-10.00$ \\
\hline \multirow{2}{*}{$\begin{array}{l}\text { Close margin ( }<5 \mathrm{~mm} \text { by histopa- } \\
\text { thology) }\end{array}$} & No & 95 & 0.582 & 0.0901 & & \\
\hline & Yes & 7 & 0.429 & & 10.97 & $2.77-43.43$ \\
\hline
\end{tabular}

$B M I$ body mass index, $C R P C$-reactive protein, $P N /$ prognostic nutritional index, $D F S$ disease-free survival

resolution of the extracellular matrix and neovascularization. Consequently, growth, invasion, and metastasis of tumors are accelerated. However, it is difficult to easily measure these cytokines $[49,50]$. Blood biochemical changes caused by these cytokines can be assessed by measuring inflammatory reaction markers based on the systemic inflammatory reaction. [46-51]. To date, numerous traditional systemic inflammation markers have been reported, including the Glasgow Prognostic Score $[52,53]$ based on plasma components, the neutrophil-to-lymphocyte ratio [54, 55] derived from the number of blood cells, the lymphocyte-to-monocyte ratio [56, 57], CRP-to-albumin ratio [58], and the PNI $[27,59]$ based on serum albumin levels and lymphocyte 


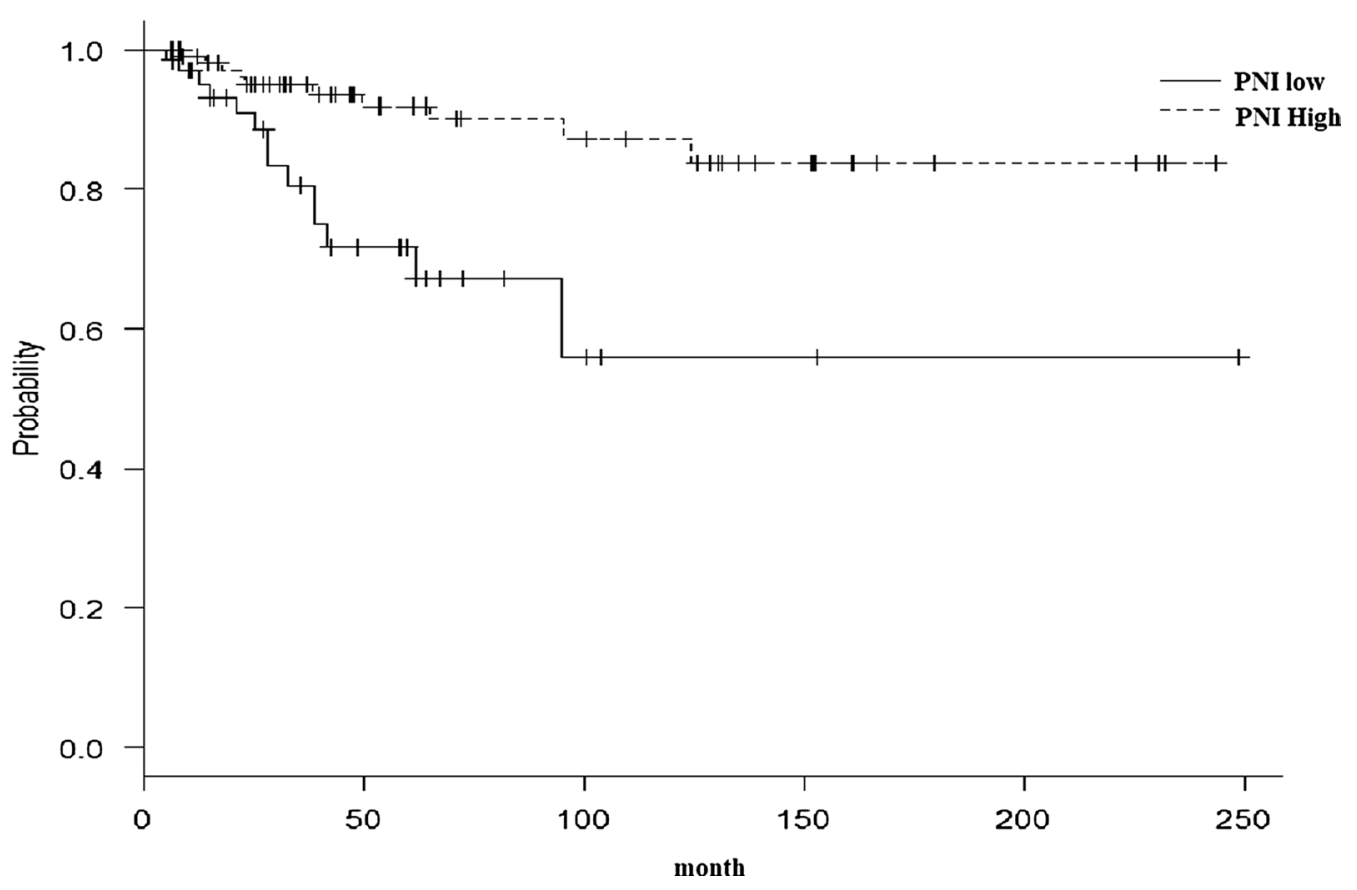

Fig. 3 Kaplan-Meier survival curves for the PNI and overall survival of oral squamous cell carcinoma patients. Kaplan-Meier curves, according to the PNI score. The OS was significantly worse in patients with a lower PNI than those with a higher PNI $(\geq 42.9)(P=0.0007886$, respectively). PNI prognostic nutritional index, OS overall survival

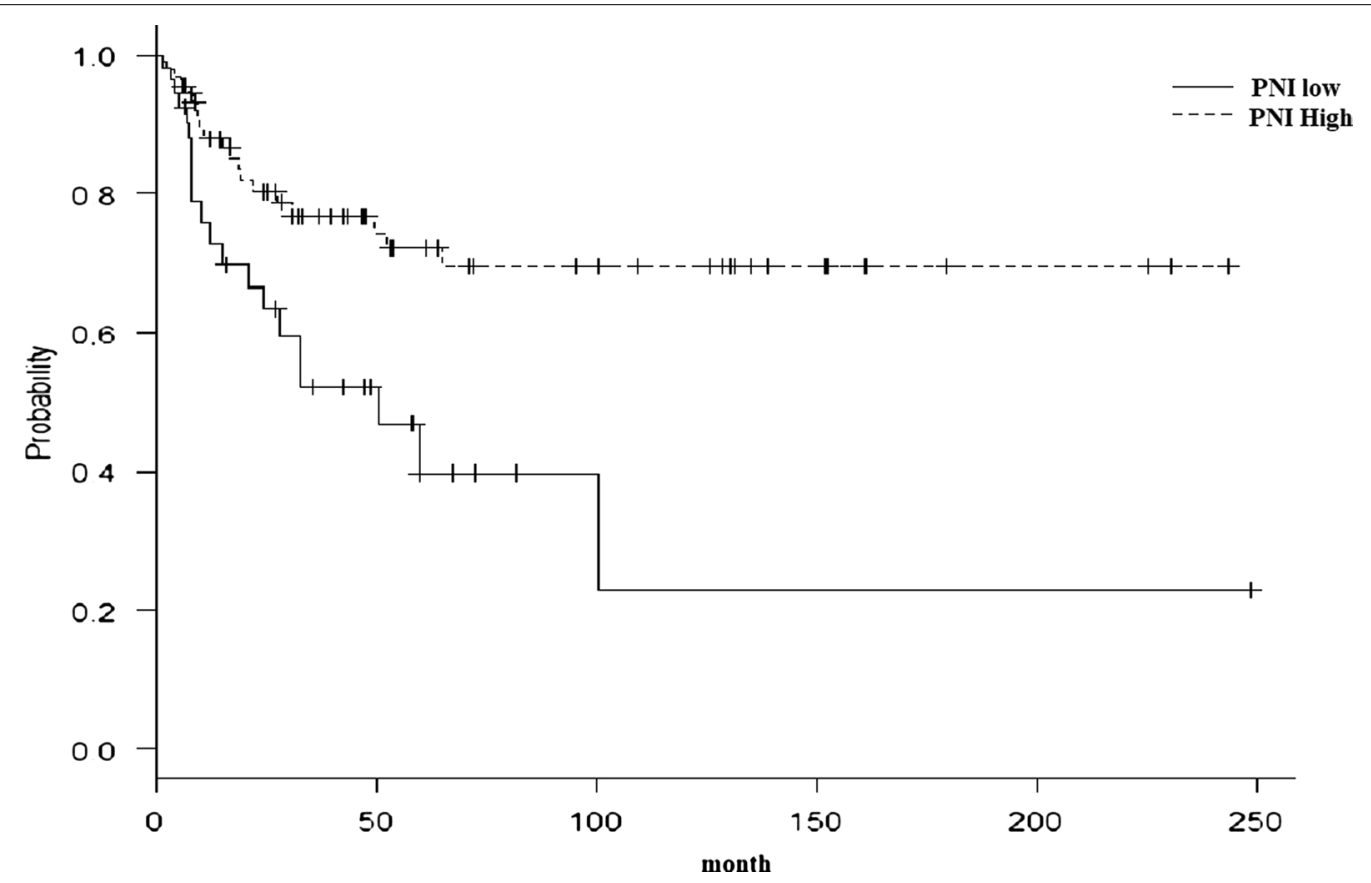

Fig. 4 Kaplan-Meier survival curves for the PNI and the DFS of oral squamous cell carcinoma patients. Kaplan-Meier curves, according to the PNI score. The DFS was significantly worse in patients with lower PNI than those with a higher PNI $(\geq 42.9)(P=0.000005792$, respectively). PNI prognostic nutritional index, DFS disease-free survival 


\begin{tabular}{|c|c|c|c|}
\hline Variables & Hazard ratio & $95 \% \mathrm{Cl}$ & $\mathrm{p}$ value \\
\hline CRP & 3.56 & $1.41-9.01$ & 0.0073 \\
\hline Grade & 0.21 & $0.04-1.12$ & 0.068 \\
\hline PNI & 0.25 & $0.10-0.66$ & 0.0047 \\
\hline Stage & 2.48 & $0.96-6.40$ & 0.061 \\
\hline Lymphovascular invasion & 1.25 & $0.50-3.11$ & 0.64 \\
\hline Vascular invasion & 3.29 & $0.88-12.20$ & 0.076 \\
\hline Perineural invasion & 4.7 & $1.04-21.25$ & 0.044 \\
\hline $\begin{array}{l}\text { Close margin ( }<5 \mathrm{~mm} \text { by } \\
\text { histopathology) }\end{array}$ & 2.15 & $0.37-12.51$ & 0.39 \\
\hline Postoperative treatment & 1.45 & $0.54-3.91$ & 0.46 \\
\hline
\end{tabular}

CRP C-reactive protein, $P N I$ prognostic nutritional index, OS overall survival

\begin{tabular}{|c|c|c|c|}
\hline Variables & Hazard ratio & $95 \% \mathrm{Cl}$ & $\mathrm{p}$ value \\
\hline CRP & 1.75 & $0.89-3.44$ & 0.11 \\
\hline Grade & 1.7 & $0.52-5.57$ & 0.38 \\
\hline $\mathrm{PNI}$ & 0.37 & $0.19-0.73$ & 0.0043 \\
\hline Stage & 1.09 & $0.50-2.38$ & 0.83 \\
\hline Lymphovascular invasion & 1.62 & $0.80-3.29$ & 0.18 \\
\hline Vascular invasion & 1.1 & $0.32-3.79$ & 0.88 \\
\hline Perineural invasion & 0.65 & $0.17-2.52$ & 0.53 \\
\hline $\begin{array}{l}\text { Close margin ( }<5 \mathrm{~mm} \text { by } \\
\text { histopathology) }\end{array}$ & 4.49 & $1.30-15.53$ & 0.018 \\
\hline Postoperative treatment & 3.08 & $1.39-6.81$ & 0.0054 \\
\hline
\end{tabular}

$C R P C$-reactive protein, $P N /$ prognostic nutritional index, DFS disease-free survival

counts. Most of these markers are based on blood cell counts, serum protein level measurement, and the ratios derived from these parameters. Albumin is a significant component of the plasma protein content and reflects the nutritional status, whereas lymphocytes reflect the immunological state; therefore, the ratio of serum albumin level to the lymphocyte count is associated with the survival of patients with cancer [60-62].

Low PNI levels show poor prognosis for oral cancer because the inflammatory cytokines IL- 6 and IL-8 increased the number of neutrophils and decreased those of lymphocytes besides enhancing proteolysis [48-51]. Thus, low PNI was considered as an indicator of high inflammatory cytokine levels. The release of cytokines by cancer cells results in a rise in the serum CRP level at the same time. Elevated CRP levels have been reported to be associated with a lower rate of DFS and OS in operable oral cancers [62]. Similarly, some reports have investigated the impact of serum albumin and CRP on the outcome of combination chemoradiotherapy in cases of unresectable head and neck cancers [63]. The association between OS and CRP has been reflected in this study.

The mechanisms underlying the associations between systemic inflammatory response and survival in patients with oral squamous cell carcinoma are not evident. However, using albumin levels and lymphocyte counts, the components used for PNI calculation, cancer cachexia associated with growth factors release, impaired cellmediated immune response, and angiogenesis can be estimated [64-68]. These mechanisms are complex and include a combination of the factors mentioned above. Therefore, further studies involving metrics such as the PNI, along with an appropriate grading system for it, are necessary to assess its prognostic value in oral cancer. We incorporated the PNI in a prognostic model, and the prospective analysis of this model in a large group of patients was essential to assess the pretreatment risk. In the following paragraphs, we provide some hypotheses to explain why a low PNI level is associated with a poor prognosis for oral cancer.

First, the levels of serum albumin, which is a chief component of plasma proteins, can reflect the nutritional status, while lymphocytes, which can eliminate cancer cells and are important components of the immune system, can reflect the immunological state. Thus, the PNI reflects the nutritional and immunological states of the host and can indicate the prognosis in patients with cancer. Consistent with this, the results of some studies have shown that the PNI, after an adjustment for other risk factors, was an independent prognostic factor for the OS.

Second, a low PNI has been reported to be associated with poorer tumor prognosis (increased depth of tumor, lymph node metastasis, poor TNM staging), and an extensive hematic and lymphatic spread. In the multivariate analysis, a significant association was observed between perineural invasion and OS. Cytokines may promote perineural invasion; however, the relationship between such invasion and the PNI is not clear at the moment. Perineural invasion and its relation to PNI are future research themes in oral squamous cell carcinoma.

Multivariate analysis also showed a significant association of the surgical margin, postoperative treatment, and PNI with the DFS. Therefore, PNI has a role in predicting DFS. Moreover, a low PNI is associated with malnutrition and immunosuppression and may inhibit the success of chemoradiotherapy. In this context, PNI can be thought of as having a prognostic value in predicting DFS.

These results suggest that in evaluating systemic inflammatory response in oral cancer, a blood protein reflects the actual situation rather than the blood cells. This suggestion is consistent with a previously published report [27]. 
Using clinical background factors including the PNI, we performed single multivariate analyses, including factors that are most related to prognosis, and found that a low PNI value was related to prognosis. These results suggest that the PNI is independent of clinical background and surgical-related factors and that the relationship between the PNI and the prognosis may involve a different mechanism from that associated with tumor markers. These results suggest that PNI can predict the prognosis of oral cancer before surgery.

A limitation of this study is the retrospective analysis of data from a single facility. Additionally, the ROC, when determining the cutoff value was relatively low, affected by a treatment protocol, and the number of samples in this study was likely not sufficient (102 cases). Furthermore, since the median observation period was as short as 48.1 months, an increase in the number of cases and longer observation periods are essential. In cases involving metastasis or inflammation, inflammatory cytokines increase the production of acute-phase proteins such as CRP in the liver and reduce the production of albumin. Therefore, when examining a condition including an inflammatory response and considering the change in nutritional status using biomarkers, it should be assumed that the inflammatory response (CRP and white blood cell count) is normal and does not vary [57]. Whether low PNI is the cause or the effect of tumor progression remains unknown, and additional research is required to elucidate this problem.

The assessments of the PNI are cheaper than those involving tumor markers, and the PNI can be easily calculated using blood samples. Therefore, the PNI can be a prognostic factor for OS and may be a useful long-term marker for evaluating recurrence and metastasis before postoperative chemoradiotherapy and during follow-up. Furthermore, poor nutritional status leads to delay and abandonment of postoperative adjuvant therapy and immunological treatment. Thus, these findings may partially explain the relationship between low OS and low $\mathrm{PNI}$ in patients with oral cancer.

\section{Conclusions}

The PNI, a cheaper alternative to tumor markers that can be easily measured using common preoperative blood sampling techniques, can be a prognostic tool to assess the OS. This may partially explain its relationship with the survival period in patients with oral cancer. Moreover, it can be a useful long-term prognostic marker for assessing the recurrence, metastasis, and follow-up assessments. Furthermore, PNI assessments may facilitate the choice between postoperative chemoradiotherapy and adjuvant therapy.

\section{Abbreviations}

BMI: Body mass index; CRP: C-reactive protein; Cl: Confidence interval; HR: Hazard ratio; IL: Interleukin; OS: Overall survival; PNI: Prognostic nutritional index; ROC: Receiver operating characteristic.

\section{Acknowledgements}

We would like to thank Editage Science Communications for English language editing and publication support.

\section{Authors' contributions}

AA conceived the study, carried out the design and coordination, wrote the manuscript, and gave the final approval of the version to be submitted. HF critically revised the manuscript for important intellectual content. $\mathrm{HH}$ and TI collected the clinical data and drafted the article. All authors read and approved the final manuscript.

\section{Funding}

The present research did not receive any specific grant from funding agencies in the public, commercial, or not-for-profit sectors.

\section{Availability of data and materials}

The raw data are confdential and cannot readily be shared. Researchers need to obtain permission from the Institutional Review Board and apply for access to the data from The Ethics Committee of Nagoya Ekisaikai Hospital.

\section{Ethics approval and consent to participate}

All procedures were performed in accordance with the ethical standards of the institutional and/or national research committee and in line with the 1964 Declaration of Helsinki. The present retrospective cohort study was approved by the Nagoya Ekisaikai Hospital Institutional Review Board (approval number 2019-046). The ethics committee approved the procedure of this study and gave us administrative permissions to access the data used in this study. The study was conducted in accordance with the Strengthening the Reporting of Observational Studies in Epidemiology (STROBE) Statement guidelines for reporting observational studies.

\section{Consent to publication}

Not applicable.

\section{Competing interests}

The authors declare that they have no competing interests.

Received: 20 April 2020 Accepted: 11 January 2021

Published online: 22 January 2021

\section{References}

1. Ferlay J, Colombet M, Soerjomataram I, Mathers C, Parkin DM, Piñeros $M$, et al. Estimating the global cancer incidence and mortality in 2018 GLOBOCAN sources and methods. Int J Cancer. 2019;144:1941-53.

2. Pfister DG, Ang KK, Brizel DM, Burtness BA, Busse PM, Caudell JJ, et al. Head and neck cancers, version 2.2013. Featured updates to the NCCN guidelines. J Natl Compr Canc Netw. 2013;11:917-23.

3. McMahon J, O'Brien CJ, Pathak I, Hamill R, McNeill E, Hammersley N, et al. Influence of condition of surgical margins on local recurrence and disease- specific survival in oral and oropharyngeal cancer. Br J Oral Maxillofac Surg. 2003;41:224-31.

4. Capote-Moreno A, Naval L, Muñoz-Guerra MF, Sastre J, RodríguezCampo FJ. Prognostic factors influencing contralateral neck lymph node metastases in oral and oropharyngeal carcinoma. J Oral Maxillofac Surg. 2010;68:268-75.

5. Tankéré F, Camproux A, Barry B, Guedon C, Depondt J, Gehanno P. Prognostic value of lymph node involvement in oral cancers: a study of 137 cases. Laryngoscope. 2000;110:2061-5.

6. Preda L, Chiesa F, Calabrese L, Latronico A, Bruschini R, Leon ME, et al. Relationship between histologic thickness of tongue carcinoma and thickness estimated from preoperative MRI. Eur Radiol. 2006;16:2242-8. 
7. Yuen AP, Ng RW, Lam PK, Ho A. Preoperative measurement of tumor thickness of oral tongue carcinoma with intraoral ultrasonography. Head Neck. 2008;30:230-4.

8. McMillan DC. Systemic inflammation, nutritional status and survival in patients with cancer. Curr Opin Clin Nutr Metab Care. 2009;12:223-6.

9. Roxburgh CS, McMillan DC. Role of systemic inflammatory response in predicting survival in patients with primary operable cancer. Future Oncol. 2010;6:149-63.

10. Farhan-Alanie OM, McMahon J, McMillan DC. Systemic inflammatory response and survival in patients undergoing curative resection of oral squamous cell carcinoma. Br J Oral Maxillofac Surg. 2015;53:126-31.

11. Proctor MJ, Morrison DS, Talwar D, Balmer SM, O'Reilly DS, Foulis AK, et al. An inflammation-based prognostic score (mGPS) predicts cancer survival independent of tumour site: a Glasgow Inflammation Outcome Study. Br J Cancer. 2011;104:726-34.

12. Smith RA, Bosonnet L, Raraty M, Sutton R, Neoptoleamos JP, Campbell F, et al. Preoperative platelet-lymphocyte ratio is an independent significant prognostic marker in resected pancreatic ductal adenocarcinoma. Am J Surg. 2009;197:466-72.

13. Halazun KJ, Aldoori A, Malik HZ, Al-Mukhtar A, Prasad KR, Toogood GJ, et al. Elevated preoperative neutrophil to lymphocyte ratio predicts survival following hepatic resection for colorectal liver metastases. Eur J Surg Oncol. 2008;34:55-60.

14. Proctor MJ, Morrison DS, Talwar D, Balmer SM, Fletcher DS, O'Reilly DS, et al. A comparison of inflammation-based prognostic scores in patients with cancer. A Glasgow Inflammation Outcome Study. Eur J Cancer. 2011:47:2633-41.

15. Feng JF, Huang Y, Liu JS. Combination of neutrophil to lymphocyte ratio and platelet lymphocyte ratio as a useful predictor of postoperative survival in patients with esophageal squamous cell carcinoma. Onco Targets Ther. 2013;6:1605-12.

16. Teramukai S, Kitano T, Kishida Y, Kawahara M, Kubota K, Komuta K, et al. Pretreatment neutrophil count as an independent prognostic factor in advanced non-small-cell lung cancer: an analysis of Japan Multinational Trial Organisation LC00-03. Eur J Cancer. 2009;45:1950-8.

17. Halazun KJ, Hardy MA, Rana AA, Woodland DC IV, Luyten EJ, Mahadev $S$, et al. Negative impact of neutrophil-lymphocyte ratio on outcome after liver transplantation for hepatocellular carcinoma. Ann Surg. 2009;250:141-51.

18. Wang DS, Luo HY, Qiu MZ, Wang ZQ, Zhang DS, Wang FH, et al. Comparison of the prognostic values of various inflammation based factors in patients with pancreatic cancer. Med Oncol. 2012;29:3092-100.

19. Pan QX, Su ZJ, Zhang JH, Wang CR, Ke SY. A comparison of the prognostic value of preoperative inflammation-based scores and TNM stage in patients with gastric cancer. Onco Targets Ther. 2015;8:1375-85.

20. Xue Y, Zhou X, Xue L, Zhou R, Luo J. The role of pretreatment prognostic nutritional index in esophageal cancer: a meta-analysis. J Cell Physiol. 2019;234:19655-62.

21. Guner A, Kim HI. Biomarkers for evaluating the inflammation status in patients with cancer. J Gastric Cancer. 2019;19:254-77.

22. McMillan DC. The systemic inflammation based Glasgow Prognostic Score: a decade of experience in patients with cancer. Cancer Treat Rev. 2013;39:534-40.

23. Moon H, Roh JL, Lee SW, Kim SB, Choi SH, Nam SY, et al. Prognostic value of nutritional and hematologic markers in head and neck squamous cell carcinoma treated by chemoradiotherapy. Radiother Oncol. 2016;118:330-4

24. Xue Y, Zhou X, Xue L, Zhou R, Luo J. The role of pretreatment prognostic nutritional index in esophageal cancer: a meta-analysis. J Cell Physiol. 2019;234(11):19655-62.

25. Seaton K. Albumin concentration controls cancer. J Natl Med Assoc. 2001;93(12):490-3.

26. Gupta D, Lis CG. Pretreatment serum albumin as a predictor of cancer survival: a systematic review of the epidemiological literature. Nutr J. 2010;9:69.

27. Yang $Y$, Gao P, Song Y, Sun J, Chen $X$, Zhao J, et al. The prognostic nutritional index is a predictive indicator of prognosis and postoperative complications in gastric cancer: a meta-analysis. Eur J Surg Oncol. 2016;42:1176-82.

28. Fu Y, Chen SW, Chen SQ, Ou-Yang D, Liu WW, Song M, et al. A preoperative nutritional index for predicting cancer-specific and overall survival in
Chinese patients with laryngeal cancer: a retrospective study. Medicine (Baltimore). 2016;95:e2962.

29. Head and Neck Cancer Study Group (HNCSG), Monden N, Asakage T, Kiyota N, Homma A, Matsuura K, et al. A review of head and neck cancer staging system in the TNM classification of malignant tumors (eighth edition). Jpn J Clin Oncol. 2019;49:589-95.

30. Onodera T, Goseki N, Kosaki G. Prognostic nutritional index in gastrointestinal surgery of malnourished cancer patients. Nihon Geka Gakkai Zasshi. 1984;85:1001-5 ((in Japanese)).

31. Du XJ, Tang LL, Mao YP, Guo R, Sun Y, Lin AH, Ma J. Value of the prognostic nutritional index and weight loss in predicting metastasis and long-term mortality in nasopharyngeal carcinoma. J Transl Med. 2015;13:364. https ://doi.org/10.1186/s12967-015-0729-0.

32. Feng Z, Wen H, Ju X, Bi R, Chen X, Yang W, Wu X. The preoperative prognostic nutritional index is a predictive and prog-nostic factor of high-grade serous ovarian cancer. BMC Cancer. 2018;18(1):883.

33. Kang $M$, Chang $C T$, Sung $H H$, Jeon $H G$, Jeong $B C$, Seo SI, et al. Prognostic significance of pre- to postoperative dynamics of the prognostic nutritional index for patients with renal cell carcinoma who underwent radical nephrectomy. Ann Surg Oncol. 2017;24(13):4067-75. https://doi. org/10.1245/s10434-017-6065-2.

34. Okadome K, Baba Y, Yagi T, Kiyozumi Y, Ishimoto T, Iwatsuki M, Baba H. Prognostic nutritional index, tumorinfiltrating lymphocytes, and prognosis in patients with esophageal cancer. Ann Surg. 2018. https://doi. org/10.1097/SLA.0000000000002985.

35. Pinato DJ, North BV, Sharma R. A novel, externally validated inflammationbased prognostic algorithm in hepatocellular carcinoma: the prognostic nutritional index (PNI). Br J Cancer. 2012;106(8):1439-45. https://doi. org/10.1038/bjc.2012.92.

36. Nozoe T, Ninomiya M, Maeda T, Matsukuma A, Nakashima H, Ezaki T. Prognostic Nutritional Index: a tool to predict the biological aggressiveness of gastric carcinoma. Surg Today. 2010;40(5):440-3. https://doi.org/10.1007/ s00595-009-4065-y.

37. Kanda M, Fujii T, Kodera Y, et al. Nutritional predictors of postoperative outcome in pancreatic cancer. The British journal of surgery. 2011;98:268-74.

38. Ishizuka M, Oyama Y, Abe A, Tago K, Tanaka G, Kubota K. Prognostic nutritional index is associated with survival after total gastrectomy for patients with gastric cancer. Anticancer Res. 2014;34:4223-9.

39. Migita K, Takayama T, Saeki K, Matsumoto S, Wakatsuki K, Enomoto K, et al. The prognostic nutritional index predicts long-term outcomes of gastric cancer patients independent of tumor stage. Ann Surg Oncol. 2013;20:2647-54.

40. Watanabe M, Iwatsuki M, Iwagami S, Ishimoto T, Baba Y, Baba H. Prognostic nutritional index predicts outcomes of gastrectomy in the elderly. World J Surg. 2012;36:1632-9.

41. Kinoshita A, Onoda H, Imai N, Iwaku A, Oishi M, Tanaka K, et al. The C-reactive protein/albumin ratio, a novel inflammation-based prognostic score, predicts outcomes in patients with hepatocellular carcinoma. Ann Surg Oncol. 2015;22:803-10.

42. Ishizuka M, Nagata H, Takagi K, Iwasaki Y, Shibuya N, Kubota K. Clinical significance of the C-reactive protein to albumin ratio for survival after surgery for colorectal cancer. Ann Surg Oncol. 2016;23:900-7.

43. Pinato DJ, North BV, Sharma R. A novel, externally validated inflammationbased prognostic algorithm in hepatocellular carcinoma: the prognostic nutritional index (PNI). Br J Cancer. 2012;106:1439-45.

44. Buzby GP, Mullen JL, Matthews DC, Hobbs CL, Rosato EF. Prognostic nutritional index in gastrointestinal surgery. Am J Surg. 1980;139:160-7.

45. Ray-Coquard I, Cropet C, Van Glabbeke M, Sebban C, Le Cesne A, Judson I, et al. Lymphopenia as a prognostic factor for overall survival in advanced carcinomas, sarcomas, and lymphomas. Cancer Res. 2009;69:5383-91.

46. Hanahan D, Weinberg RA. The hallmarks of cancer. Cell. 2000;100:57-70.

47. Hanahan D, Weinberg RA. Hallmarks of cancer: the next generation. Cell. 2011;144:646-74.

48. Roxburgh CS, McMillan DC. Cancer and systemic inflammation: treat the tumour and treat the host. Br J Cancer. 2014;110:1409-12.

49. Haqqani AS, Sandhu JK, Birnboim HC. Expression of interleukin-8 promotes neutrophil infiltration and genetic instability in mutatect tumors. Neoplasia. 2000;2:561-8. 
50. Strieter RM, Burdick MD, Mestas J, Gomperts B, Keane MP, Belperio JA. Cancer CXC chemokine networks and tumour angiogenesis. Eur J Cancer. 2006;42:768-78.

51. Diakos Cl, Charles KA, McMillan DC, Clarke SJ. Cancer-related inflammation and treatment effectiveness. Lancet Oncol. 2014;15:e493-503.

52. Forrest LM, McMillan DC, McArdle CS, Angerson WJ, Dunlop DJ. Comparison of an inflammation-based prognostic score (GPS) with performance status (ECOG) in patients receiving platinum-based chemotherapy for inoperable non-small-cell lung cancer. Br J Cancer. 2004;90:1704-6.

53. Zhang CX, Wang SY, Chen SQ, Yang SL, Wan L, Xiong B. Association between pretreatment Glasgow prognostic score and gastric cancer survival and clinicopathological features: a meta-analysis. Onco Targets Ther. 2016;9:3883-91.

54. Shimada H, Takiguchi N, Kainuma O, Soda H, Ikeda A, Cho A, et al. High preoperative neutrophil-lymphocyte ratio predicts poor survival in patients with gastric cancer. Gastric Cancer. 2010;13:170-6.

55. Proctor MJ, McMillan DC, Morrison DS, Fletcher CD, Horgan PG, Clarke SJ. A derived neutrophil to lymphocyte ratio predicts survival in patients with cancer. Br J Cancer. 2012;107:695-9.

56. Nishijima TF, Muss HB, Shachar SS, Tamura K, Takamatsu Y. Prognostic value of lymphocyte-to-monocyte ratio in patients with solid tumors: a systematic review and meta-analysis. Cancer Treat Rev. 2015;41:971-8.

57. Huang Y, Feng JF. Low preoperative lymphocyte to monocyte ratio predicts poor cancer-specific survival in patients with esophageal squamous cell carcinoma. Onco Targets Ther. 2015;8:137-45.

58. Chen XL, Xue L, Wang W, Chen HN, Zhang WH, Liu K, et al. Prognostic significance of the combination of preoperative hemoglobin, albumin, lymphocyte and platelet in patients with gastric carcinoma: a retrospective cohort study. Oncotarget. 2015;38:41370-82.

59. Kinoshita A, Onoda H, Imai N, Iwaku A, Oishi M, Fushiya N, et al. Comparison of the prognostic value of inflammation-based prognostic scores in patients with hepatocellular carcinoma. Br J Cancer. 2012;107:988-93.

60. Taylor BE, McClave SA, Martindale RG, Warren MM, Johnson DR, Braunschweig C, et al. Guidelines for the provision and assessment of nutrition support therapy in the adult critically ill patient: Society of Critical Care
Medicine (SCCM) and American Society for Parenteral and Enteral Nutrition (A. S. P. E. N.). Crit Care Med. 2016;44:390-438.

61. Mohri T, Mohri Y, Shigemori T, Takeuchi K, Itoh Y, Kato T. Impact of prognostic nutritional index on long-term outcomes in patients with breast cancer. World J Surg Oncol. 2016;14:170.

62. Salas S, Deville JL, Giorgi R, Pignon T, Bagarry D, Barrau K, et al. Nutritional factors as predictors of response to radio-chemotherapy and survival in unresectable squamous head and neck carcinoma. Radiother Oncol. 2008;87:195-200

63. Chen HH, Chen IH, Liao CT, Wei FC, Lee LY, Huang SF. Preoperative circulating C-reactive protein levels predict pathological aggressiveness in oral squamous cell carcinoma: a retrospective clinical study. Clin Otolaryngol. 2011;36:147-53.

64. Fearon KC, Voss AC, Hustead DS, Cancer Cachexia Study Group. Definition of cancer cachexia: effect of weight loss, reduced food intake, and systemic inflammation on functional status and prognosis. Am J Clin Nutr. 2006:83:1345-50

65. Du Clos TW, Mold C. C-reactive protein: an activator of innate immunity and a modulator of adaptive immunity. Immunol Res. 2004;30:261-77.

66. Krystek-Korpacka M, Matusiewicz M, Diakowska D, Grabowski K, Blachut K, Kustrzeba-Wojcocka I, et al. Acute-phase response proteins are related to cachexia and accelerated angiogenesis in gastroesophageal cancers. Clin Chem Lab Med. 2008;46:359-64.

67. de Jong KP, Hoedemakers RM, Fidler V, Bijzet J, Limburg PC, Peeters PM, et al. Portal and systemic serum growth factor and acute-phase response after laparotomy or partial hepatectomy in patients with colorectal liver metastases: a prognostic role for C-reactive protein and hepatocyte growth factor. Scand J Gastroenterol. 2004;39:1141-8.

68. Chen Z, Malhotra PS, Thomas GR, Ondrey FG, Duffey DC, Smith CW, et al. Expression of proinflammatory and proangiogenic cytokines in patients with head and neck cancer. Clin Cancer Res. 1999;5:1369-79.

\section{Publisher's Note}

Springer Nature remains neutral with regard to jurisdictional claims in published maps and institutional affiliations.
Ready to submit your research? Choose BMC and benefit from:

- fast, convenient online submission

- thorough peer review by experienced researchers in your field

- rapid publication on acceptance

- support for research data, including large and complex data types

- gold Open Access which fosters wider collaboration and increased citations

- maximum visibility for your research: over $100 \mathrm{M}$ website views per year

At BMC, research is always in progress.

Learn more biomedcentral.com/submissions 